\title{
Medical Image of the Week: Metastatic Melanoma with Hemorrhage
}

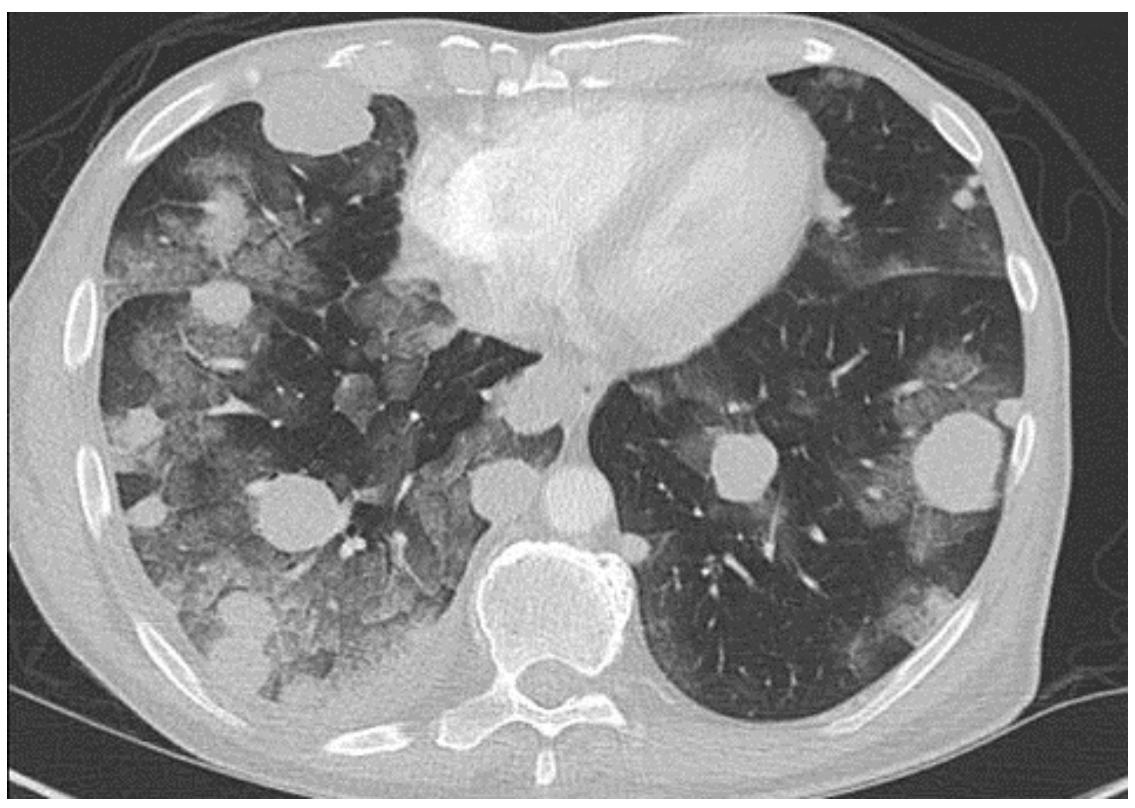

Figure 1. Axial image of CT Chest with contrast showing pulmonary metastatic masses and alveolar opacities consistent with pulmonary hemorrhage.

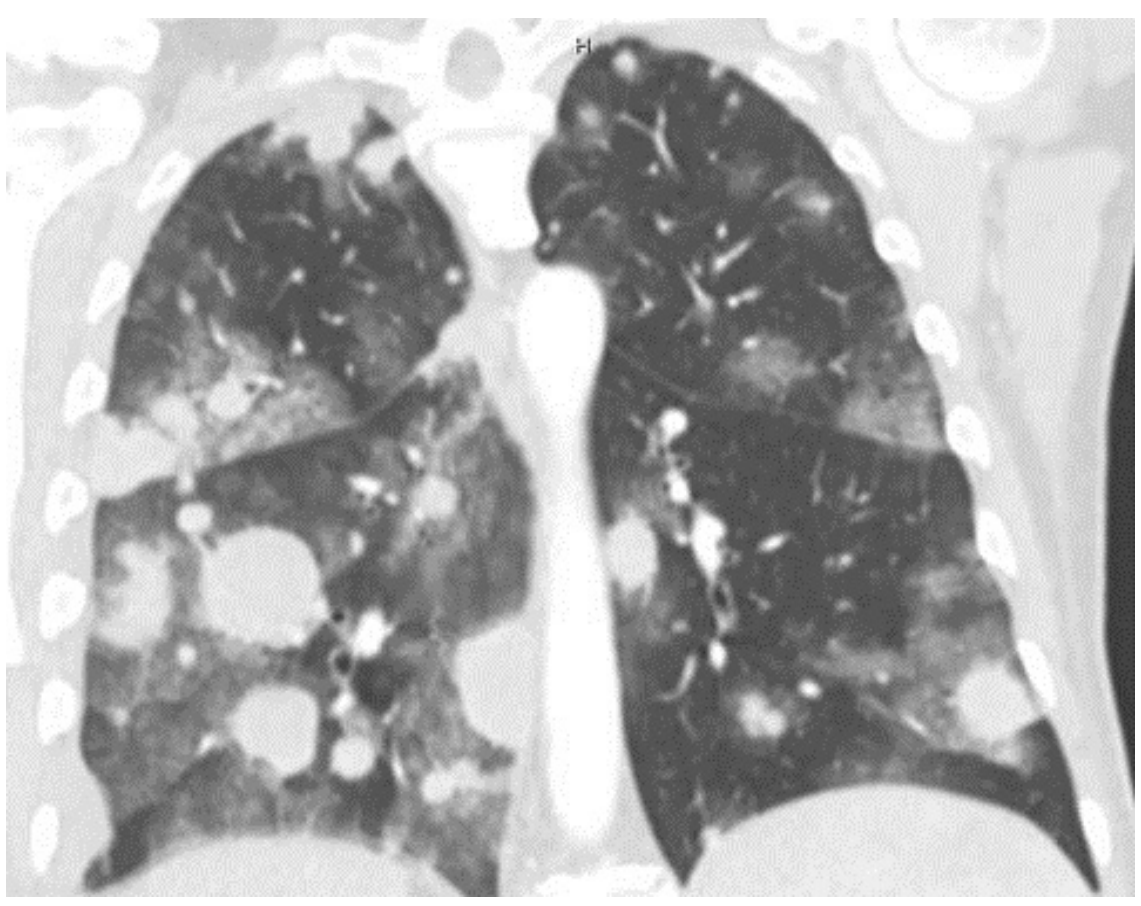

Figure 2. Coronal image of CT Chest with contrast showing innumerable pulmonary nodules and masses along with ground-glass alveolar opacities representing alveolar hemorrhage. 
A 62 year-old gentleman presented with right leg swelling due to an extensive DVT in the right femoral vein. He was found to have a right groin mass attributed to metastatic malignant melanoma. Chest x-ray and CT revealed multiple bilateral pulmonary nodules. He was started on warfarin $3 \mathrm{mg}$ daily for acute deep venous thrombosis and referred to Oncology. Two weeks later he developed hemoptysis and was found to be hypoxemic. He was admitted to our MICU. His international normalized ratio (INR) upon admission was 8.2 and hemoglobin $6.4 \mathrm{~g} / \mathrm{dL}$. CT chest showed innumerable bilateral pulmonary nodules and ground-glass alveolar opacities with thickening and nodularity of intra-lobular septa adjacent to the nodules. Warfarin was held and packed red blood cell and fresh frozen plasma transfusions were given with progressive improvement in hemoptysis and pulmonary status.

Tauseef Afaq Siddiqi, MD; Abdulmajid Eddib, MD; Phillip Factor, DO; and Steven Knoper, MD

Department of Medicine Section of Pulmonary, Allergy, Critical Care and Sleep Medicine The University of Arizona

Tucson, AZ 85724, USA 